\title{
Experimental and Numerical Study for the Shaping Formation of SCST Structures by Cable-tensioning
}

\author{
J.W. Kim ${ }^{1}$, J. H. Doh*, ${ }^{, 2}$ and S. Fragomeni ${ }^{3}$ \\ ${ }^{I}$ Department of Ocean Civil Engineering, Gyeongsang National University, Gyeongnam, 650-160, Korea \\ ${ }^{2}$ Griffith School of Engineering, Griffith University, Gold Coast Campus, Queensland 4222, Australia \\ ${ }^{3}$ School of Engineering and Science, Victoria University, Australia
}

\begin{abstract}
This paper discusses the behaviour characteristics of the shaping formation of Single-Chorded Space Truss (SCST) structures by means of cable-tensioning of bottom chords. The innovative technique is fast and economical and issued in many types of space structures. The small-scale test models presented herein consist of uniform pyramids with multi-directional ball type joints which are erected into their final shape by cable-tensioning. Since the joint behaviour is very significant in studying the shaping of SCST structures, basic tests for beam and pyramidal units were performed. The feasibility of the proposed cable-tensioning technique and the reliability of the established geometric model were confirmed by finite element analysis. The proposed cable-tensioning technique indicates that the behaviour characteristic of joints is very important in the shaping formation of SCST structures. More specifically in situations where heavy cranes are inaccessible, the cable-tensioning construction technique has proven to be an easy and reasonable method compared to conventional construction methods that typically include heavy cranes and scaffolding.
\end{abstract}

Keywords: Finite Element Analysis; Mechanism; Nonlinear; Cable-tensioning; SCST structure; Shaping Formation.

\section{INTRODUCTION}

Space trusses have been widely used ever since they were introduced commercially. They are usually utilized for overspread long-span roof coverings found in stadiums, public halls, exhibition centres, aeroplane hangers, offshore drilling platforms, power transmission towers and many other similar structures where there is a need to avoid columns. Space structures are relatively lightweight, easy to fabricate and transport, flexible enough to work into shape, pleasing in appearance and require a relatively short construction period. Recently various types of space trusses such as the barrel vault, dome, hypar and arch shaped structures have been studied using model testing and theoretical analysis for shape formation by post-tensioning [1-17]. Engineers typically consider using traditional construction methods to erect space structures, whereas consideration should also be given to innovative and cost-effective construction methods. Since shaping and erection of space structures is a major portion of the total cost, the construction method used would have a big impact on the type of structural system chosen. Using a traditional construction process may result in the need for cranes, scaffolding or even erection towers that may be complicated

*Address correspondence to this author at the Griffith School of Engineering, Griffith University, Gold Coast Campus, Queensland 4222, Australia; Tel: +61(7) 5552 9141; Fax: +61(7) 5552 8065;

E-mail: J.doh@griffith.edu.au and quite expensive. So in this study, an alternative construction method by means of cable-tensioning is proposed.

Shape formation testing and theoretical analysis for this type of space structure were conducted with test models consisting of ball type joints and steel pipes. The behaviour of such space structures is considered to be nonlinear owing to large deformations present. Through this model testing and nonlinear finite element analysis, the true behaviour characteristics and feasibility of the shaping formation for space structures with ball typed joints can be verified, and as a result the final shape of the actual space structure can be predicted.

In the initial planar configuration using the cabletensioning technique, the SCST structure can be shaped easily with relatively small cable-tensioning forces. The SCST structure can only resist its own weight, the friction of its joints, and flexural stiffness of the top chords and is therefore considered a weak structure type. However, after the cable-tensioning and self-locking process, the SCST structure can be considered stable with the ability to carry the desired load. During the cable-tensioning process, the top chord members are not stressed but undergo finite inextensional displacement. So the lengths of top chord members remain the same always [18]. Due to the existence of compressive pre-stress forces in some critical members after the shape formation, the ultimate load capacity of cabletensioned and shaped structures could be improved by stiffening only a selected number of critical members. 
Generally, because this type of SCST structure is subject to relatively small loading members of the structure are virtually not subjected to any deformation, and most of the deformation is attributed to the joint movement. As a result the behaviour characteristics of the joints are very important. Consequently experiments of beam and pyramidal units were performed to study the behaviour characteristics of the ball type joints, where the results could be used in the overall study of the shaping of SCST structures.

\section{PRINCIPLE OF CABLE-TENSIONING AND SHAPED SPACE STRUCTURE}

Numerical analysis has been applied to predict the structural shape under certain geometric and material conditions such as length, height of structure, applied load, and required stress. Shape formation of a space structure by cabletensioning provides different results depending on the type of plan layout and gap size of chord members. The basic concept of the cable-tensioning technique in the SCST structure is shown in Fig. (1). Where, cable-tensioning forces are applied to the steel cables in the tubular shaped bottom chords. With time, the gap size decreases to zero, and the structure reaches the desired shape. The length $\mathrm{L}_{\mathrm{i}}$ is the total length of bottom chord before cable-tensioning, and the length $L_{f}$ is the total length of bottom chord after cabletensioning, and this length change $\Delta \mathrm{L}$ is simulated by applying a negative temperature load at the bottom chord.

\subsection{Shape Formation Principle}

For a cable-tensioned and shaped space structure, a mechanism or near mechanism condition (flexure only in the top chords) must exist in its initial configuration, but no such mechanisms should exist in its final configuration. This requirement is necessary because the final configuration of the structure must be kinematically indeterminate to allow the final shape to be achieved with relatively small cabletensioning forces. In its final shape, the structure must be at least statically determinate to be stable and to carry external loads. In three-dimensional space, the mechanism condition of a cable-tensioned and shaped space structures can be satisfied from the following equation [1].

$$
\mathrm{R}-\mathrm{S}+\mathrm{M}=0 \text {; where } \mathrm{R}=\mathrm{b}-(3 \mathrm{j}-\mathrm{r})
$$

where, $R=$ degree of statical indeterminacy; $S=$ number of independent pre-stress states that exist; $M=$ number of independent mechanisms; $b=$ total number of members; $j=$ total number of joints; and $r=$ number of restraints on the structure. Using this criterion, a mechanism condition for a cabletensioned and shaped structure can be expressed as: $M>0$ $(R<0, S=0)$ in its initial planar layout, and $M=0(R \geq 0$, $S \geq 0$ ) in its final space shape. The geometric compatibility condition between the initial and final configuration of a cable-tensioned and shaped space structure is that all the non-gap members remain the same length (only small deflection without large strain) during the shape formation process. This test model satisfies the mechanism condition and geometric compatibility condition, which is required in the shape formation using the cable-tensioning technique.

\section{TEST OF BEAM AND PYRAMIDAL UNITS FOR THE SCST STRUCTURE}

The beam test model to investigate the behaviour of a typical ball typed joint is shown in Fig. (2). The beam members were made of $76 \times 5.5 \mathrm{~mm}$ circular hollow section (CHS) steel tubes with lengths of $1,000 \mathrm{~mm}$, with the tubes con-
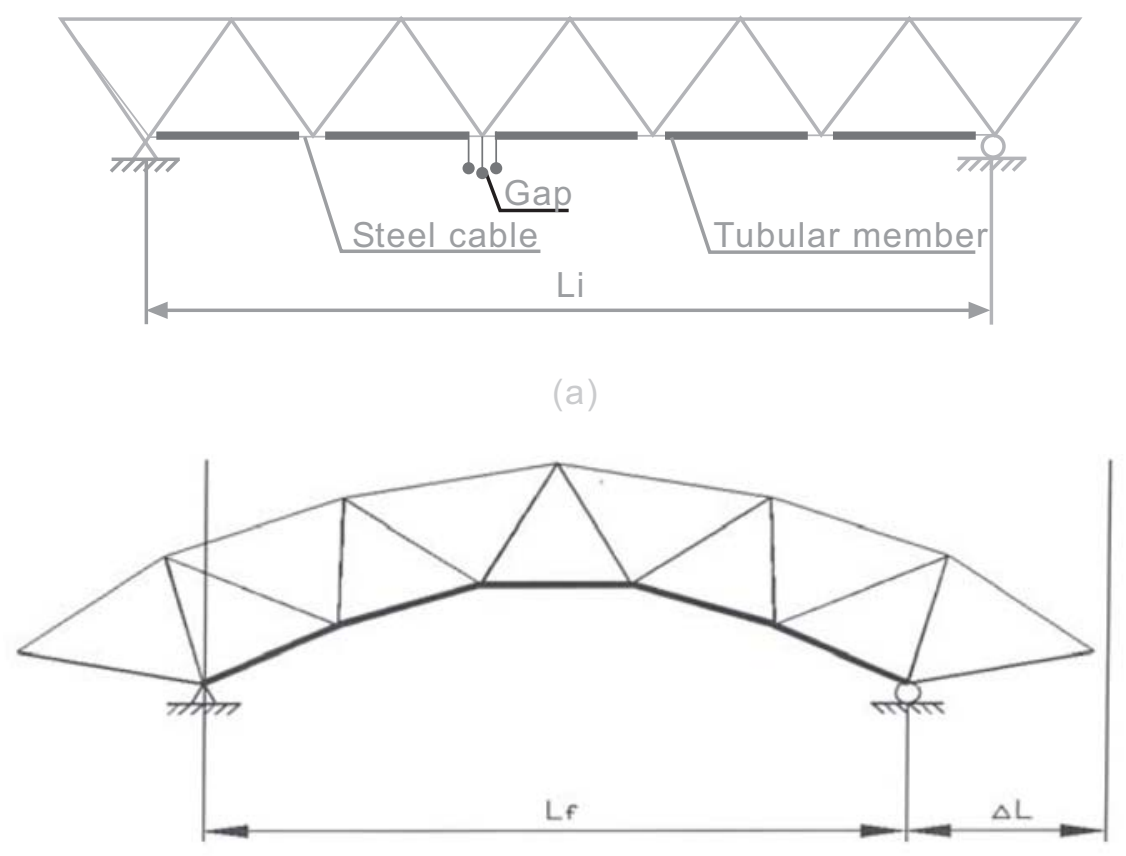

(b)

Fig. (1). Shape formation of SCST structure: (a) Before cable-tensioning in bottom chord; (b) After cable-tensioning in bottom chord. 
nected with a ball typed joint system. The properties of the steel beams were as follows: Young's modulus $E=200$ $G P a$, Poisson's ratio $v=0.3$, and the yield strength $\sigma_{y}=350$ $M P a$. The test results were used to understand the nonlinear characteristics of the shape formation in the SCST structure.

The full size scaled test model of the pyramidal unit is shown in Fig. (3). This basic pyramidal unit model is a significant representation of the space structure, since the mechanism exists, with small loading applied, and large deformation could be shown. Joint A has a horizontal and vertical support condition and Joint $C$ has a vertical support condition only. The applied load at Joint $\mathrm{C}$ is shown with the arrow notation. All members in the pyramidal unit were made of $76 \times 5.5 \mathrm{~mm}$ circular hollow section (CHS) steel tubes with lengths of 2,250 mm and $\sigma_{y}=350 \mathrm{MPa}$. As shown in Fig. (3), all the members were connected with the ball typed joint system. The load-deformation test was carried out on a strong floor, with loading provided through a hydraulic jack at Joint $\mathrm{C}$ toward the Joint A (along the direction A-C). The hand-operated hydraulic jack was connected to a load cell devise.

\section{LAYOUTS OF EXPERIMENTAL MODELS FOR SHAPING FORMATION}

As shown in Fig. (4), the space structures that are represented by the basic experimental model are the arch (Fig. 4a) and dome (Fig. 4b) shaped space structures. These structures are a three-dimensional type, with each pyramidal unit consisting of circular hollow sections (CHS), with the details of the bottom chord are described the Fig. (4c). The Young's modulus is taken as $136 \mathrm{GPa}$, Poisson's ratio and yield strength is 0.3 and $334 \mathrm{MPa}$.

\section{NONLINEAR ANALYSIS FOR TEST MODELS}

A finite element simulation of the shape formation must represent the practical procedure exactly. In such an analysis, the important design consideration is how to model the closing of the bottom chord gaps. In reality, the bottom chord is composed of separate bottom chord members connected by a continuous strand for cable-tensioning. The strand is located inside the bottom chord tubes and passed through the joints. In the finite-element analysis used, the

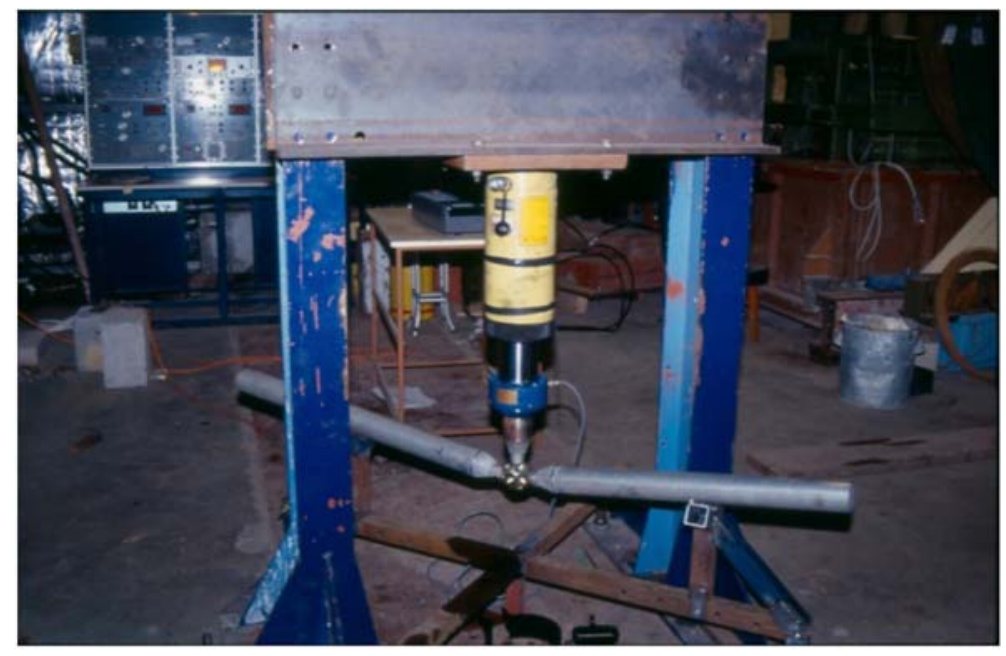

Fig. (2). Beam test for Space Structure.

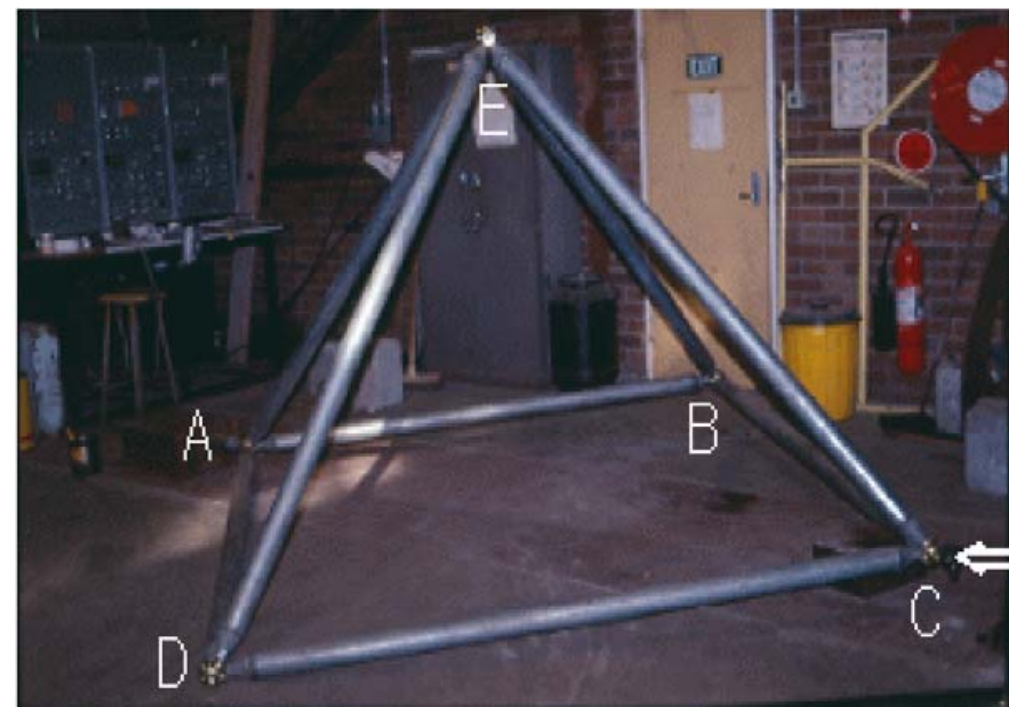

Fig. (3). Pyramidal unit test for space structure. 


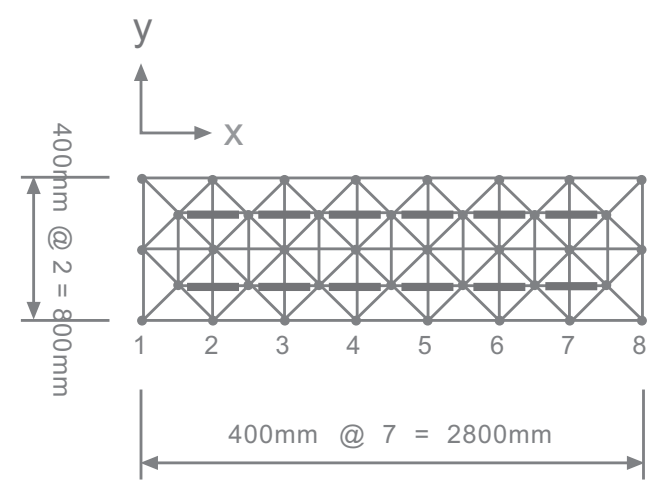

(a)

Fig. (4a). Layout of Experimental Model for arch shaped space structure.
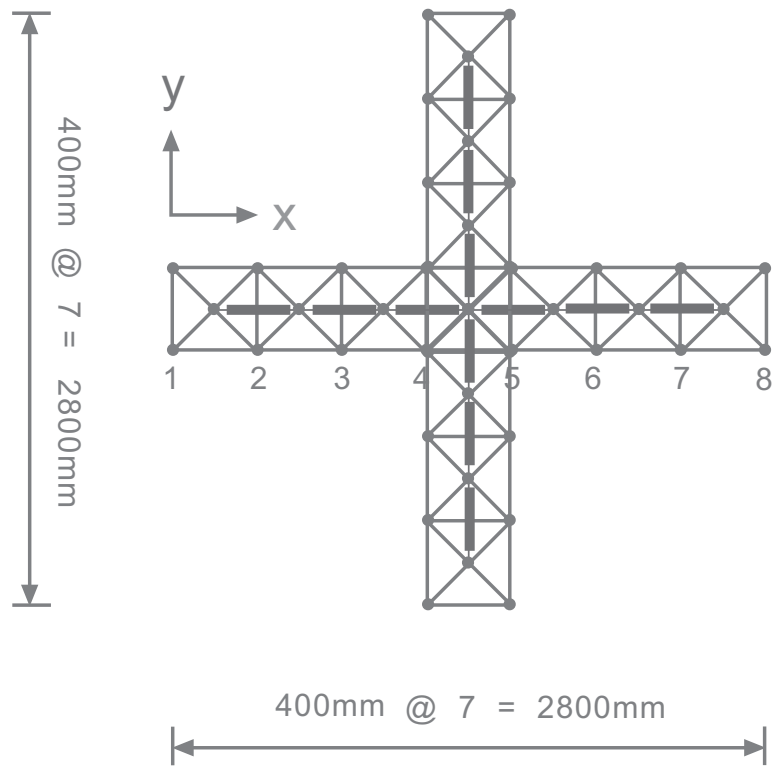

Fig. (4b). Layout of experimental model for dome shaped space structure.
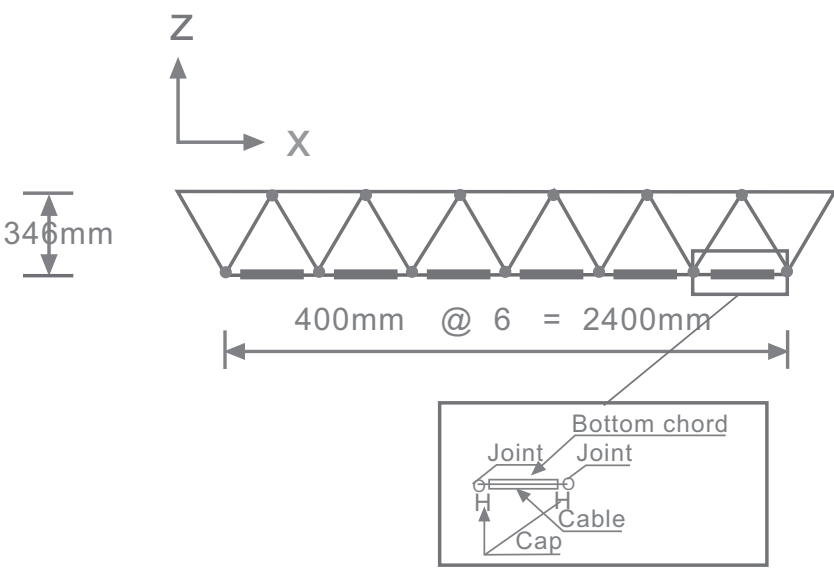

Fig. (4c). Layout of detailed bottom chord.

closing of the bottom chord gaps were simulated by element shortening caused by a negative temperature load. In considering the nonlinear characteristic structural behaviour, the commercial tool MIDAS [17] is used with the rod element. The analysis was performed using the geometric non-linear analysis as the shape formation process induces large defor- mations. The deformed shape for arch and dome shaped space structures are shown in Fig. (5). When the final space shape is determined, the cable-tensioning forces and induced stresses in each member of space structure can be obtained. These desired space shape can be formed using these predicted cable-tensioning forces, and induced stresses. 


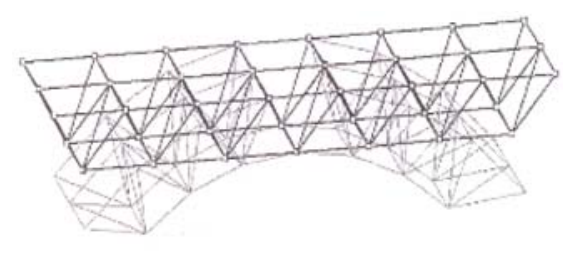

(a)

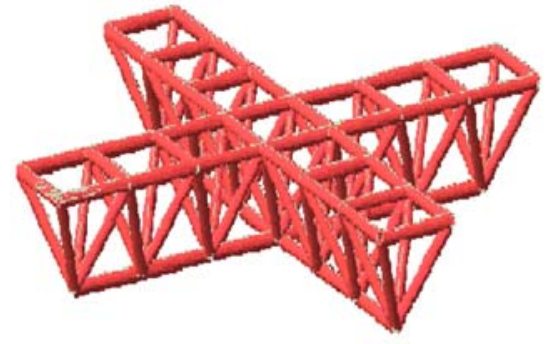

(b)

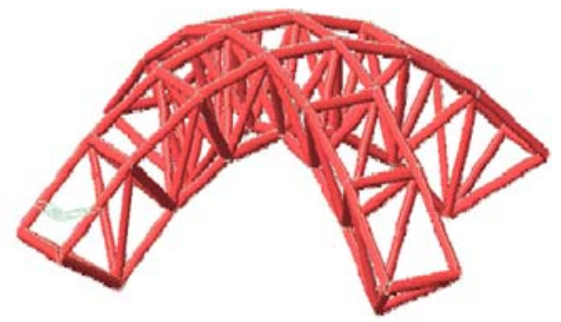

(c)

Fig. (5). Shaping of space structure deformed by nonlinear finite element analysis: (a) Deformed shape of arch shaped space structure;(b) Initial shape of dome shaped structure; (c) Deformed shape of dome shaped structure.

The experimental models were assembled on the floor by connecting the prefabricated pyramidal units, this model consist of a Circular Hollow Section (CHS) with multidirectional joints. And the size of gaps in bottom chord was closely related to the desired shape of space structure. Using the cable-tensioning technique described, the gaps of bottom chords were closed and space structure was formed into its required final shape. Consequently when the gap was completely closed between each joint of the bottom chord (i.e. there were no gaps in bottom chords), the cable-tensioning process was completed. Finally deformed arch and dome shaped space structures with including the cable-tensioning process is shown in Fig. (8).

\section{RESULTS OF EXPERIMENTS ON SHAPE FOR- MATION}

The beam and the pyramidal units in Figs $(2 \& 3)$ were tested and the results of the beam test described are given in Fig. (6). It indicates that the relationship between the load and displacement was nonlinear, although the initial portion can be considered as linear. This initial linear curve was modelled correctly theoretically using the finite element analysis. For the pyramidal unit, the behaviour characteristic for load-displacement of each joint is shown in Fig. (7). The load-displacement characteristics of lengths $\mathrm{AC}$ and BC are found to be a nonlinear, and the load-vertical displacement characteristic of the in-plane free joint $D$ is also nonlinear. All of the deformation in the pyramidal unit subjected to a small load, originated from the joint deformation rather than the members. Consequently, when the forces were applied to the beam and pyramidal unit, though the forces are small within the yielding strength, nonlinear behaviour is evident in the experimental models. With these results, we can assume that the nonlinear behaviour of test models are induced with the behaviour of ball typed joint. Fig. (9) gives the results of the shape formation of the space structure tested with the experimental structure shown in Fig. (8). The values obtained from the nonlinear finite element analysis show closer agreement to experimental values than the values obtained by linear analysis. Therefore, the nonlinear analysis should be performed when estimating the final shape of a space structure, with a cable-tensioning load required to form a ball type jointed space structure. The SCST structure can only be given a small load shaping formation, due to the induced force in the members being relatively small where the member nearly has no deformation shaping formation. Consequently, the behaviour characteristic of the joint in shaping for the space structure is more significant than that of any other member element, namely the nonlinear deformation characteristic depends on the behaviour of the joint.

Generally in this shape formation investigation, some discrepancies between theory and test results exist, which in part is due to the geometric imperfections of the member and the rotations and slippage of joints in the test model. Al-

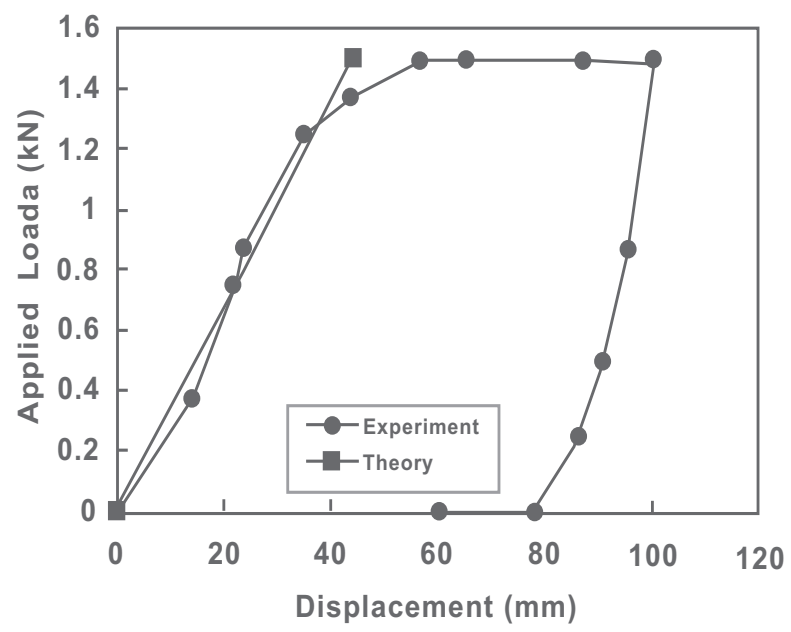

Fig. (6). Behaviour characteristic of joint in beam test.

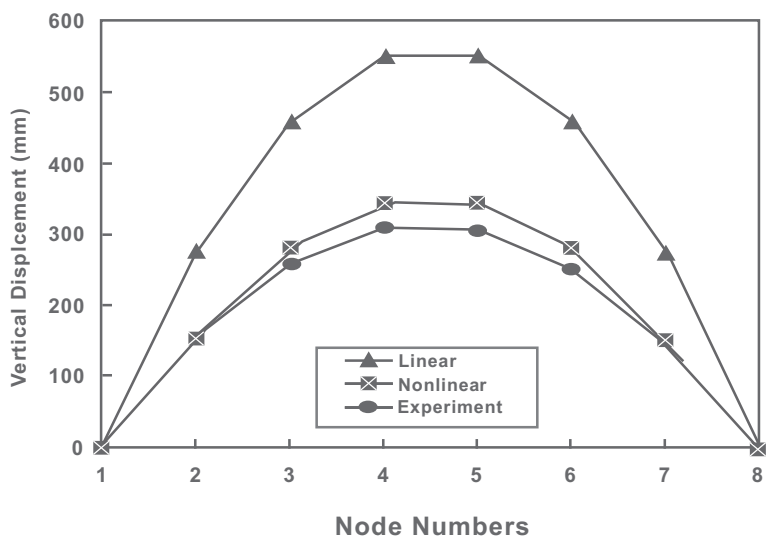

Fig. (7). Relationship between applied load and displacement of pyramidal unit. 


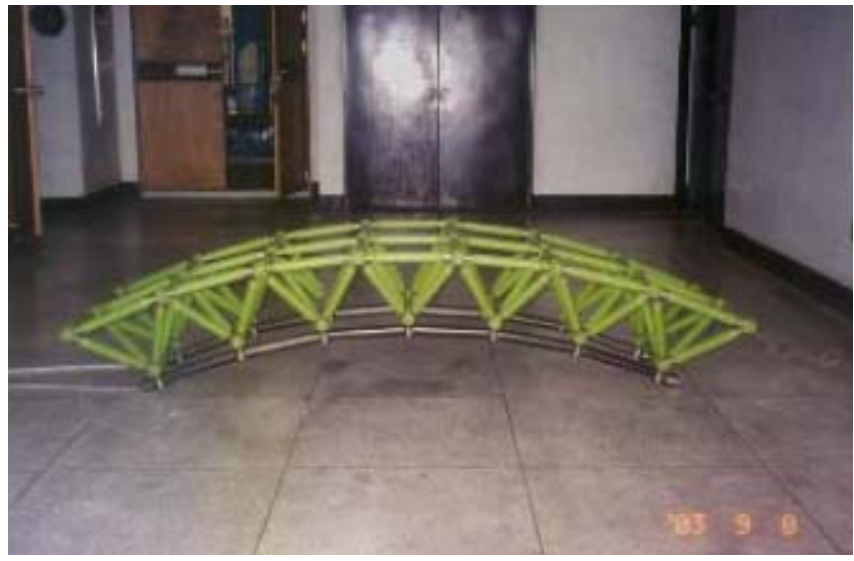

Fig. (8a) Deformed shape of arch shaped space structure by cabletensioning.

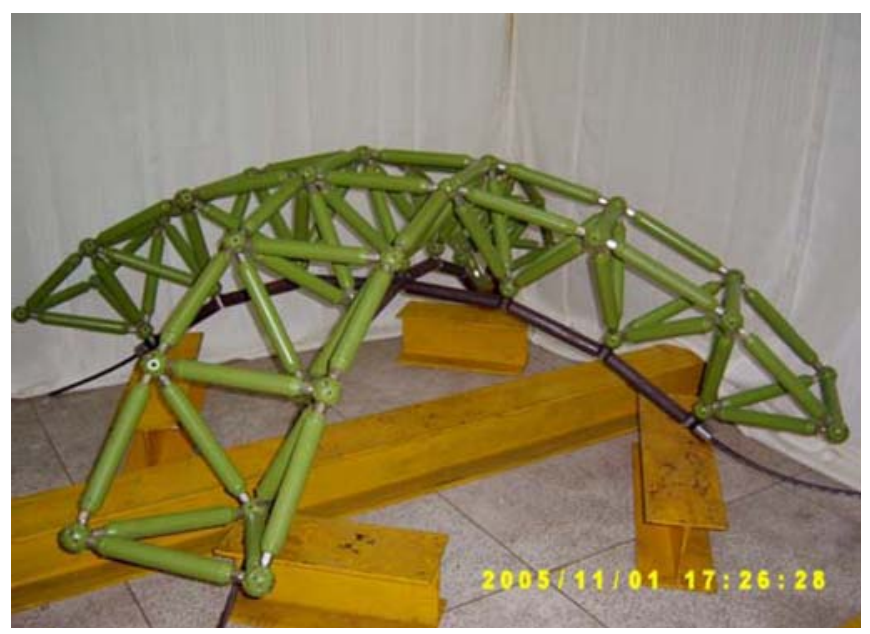

Fig. (8b) Deformed shape of dome shaped space structure by cable-tensioning.

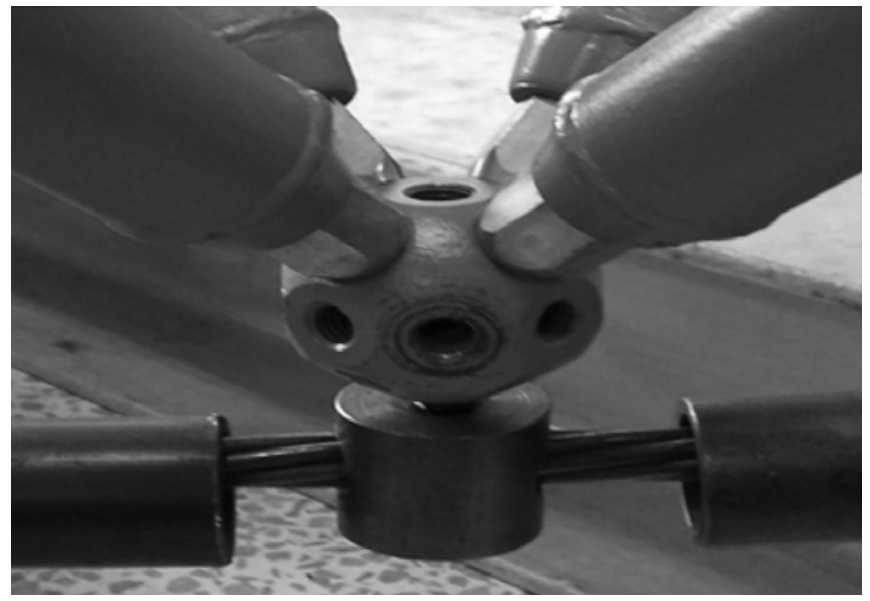

Fig. (8c) Ball typed Joint connection and gap size of space structure.

though these imperfections affect the structural behaviour of the shaping formation, it should be noted most of these factors are not considered in detail in the finite-element model. Consequently to improve the efficiency of the finite-element method for simulating the structural behaviour of shape formation of space structure, further research is necessary.

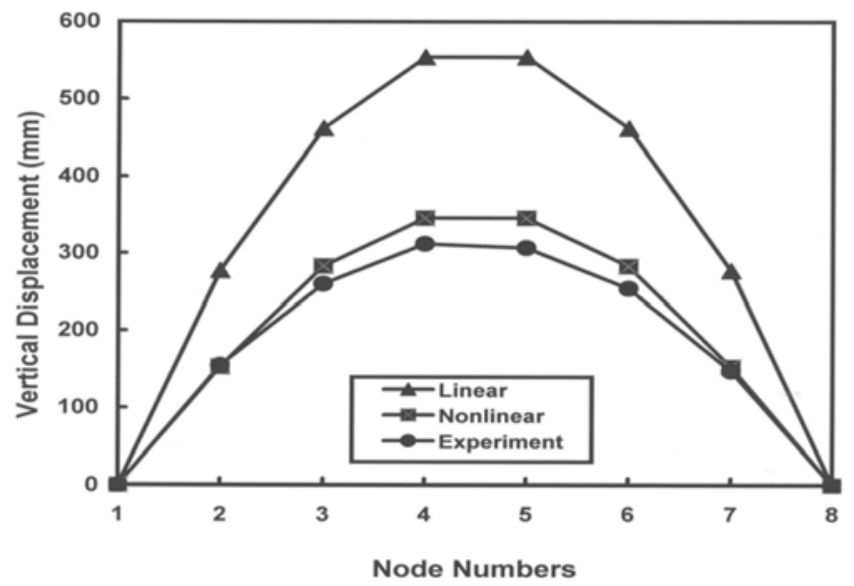

Fig. (9). Shaping characteristic of SCST space structure.

\section{CONCLUSIONS}

Through the shaping formation experiments and the nonlinear finite element analysis for ball type jointed SCST structures, the following conclusions can be drawn:

1) The test results in the beam and pyramidal units show nonlinear behaviour, meaning that joint behaviour is very important in the investigation of the shaping process.

2) In shape formation of arch and dome shaped space structures, nonlinear behaviours are evident, owing to its behaviour of joint.

3) The shape formation of a space structure with ball type joint is possible by cable-tensioning, and can be considered an economic and time saving construction technique compared to conventional techniques that use large cranes or scaffolding for erection.

4) The nonlinear finite element analysis method can be used for predicting the final space shape and the cable-tensioning forces of the shape formation of ball type jointed space structure.

\section{CONFLICT OF INTEREST}

The author(s) confirm that this article content has no conflicts of interest.

\section{ACKNOWLEDGEMENT}

None declared.

\section{REFERENCES}

[1] C. R. Calladine, “Buckminster fuller’s tensegrity struct. and clerk maxwell's rule for the construction of stiff frames", Int. J. Solids Struct., vol. 14, no. 3, pp. 161-172, 1978.

[2] M. J. Clarke, and G. J. Hancock, "Test and nonlinear analysis of small-scale stressed-arch frames”, J. Struct. Eng., ASCE, vol. 121, no. 2, pp. 187-200, 1995.

[3] G. Dehdashti, and L. C. Schmidt, "Dome-shaped space trusses formed by means of post-tensioning”, J. Struct. Eng., ASCE, vol. 122, no. 10, pp. 1240-1245, 1996. 
[4] J.W. Kim, “Analysis and test of dome-shaped space truss", $J$. the Korea Soc. Civil Eng., vol. 20, no. 1-A, pp. 39-46, 2000.

[5] J.W. Kim, "Shape creation and ultimate load test of space truss by means of posttensioning”, J. Arch. Inst. Korea, vol. 17, no. 5, pp. 51-57, 2001.

[6] J. W. Kim, and J. Hao, "Behaviour characteristic of a full-size scale pyramidal space truss unit”, KSCE J. Civil Eng., vol. 6, no. 1, pp. 33-38, 2002.

[7] J. W. Kim, and L. C. Schmidt, "Test of deployable dome-shaped space truss", In: Conference on Computing in Civil and Building Engineering (ICCCBE-VIII), ASCE, California (USA), 2000, pp. 6673.

[8] J. W. Kim, J. J. Kim, and J. W. Lee, "Form finding and experiments for three types of space trusses”, Space Struct. 5, London (UK), pp.711-720, 2002.

[9] J. W. Kim, J. J. Kim, and H. J. Rhew, "Analysis and experiment for self-erected hypar space truss", In: Proceedings of the Second Intl. Conference on Struct. Engineering, Mechanics and Computation, Cape Town (South Africa), 2004, pp. 365-369,.

[10] J. W. Kim, M. H. Kwon, and H. J. Rhew, "Shaping formation and nonlinear analysis of mero jointed space struct. with multidirectional joint”, J. Arch. Inst. Korea, vol. 121, pp. 11-18, 2005.
[11] J. W. Kim, J. J. Kim, and H. J. Rhew, “Analysis and experiment for the formation and ultimate load testing of a hypar space truss", $J$. Construct. Steel Res. vol. 62, pp.189-193, 2006.

[12] J. W. Kim, T. S. Kim, and Y. H. Lee, "Shape formation of space struct. with ball type joint”, In: Proceedings of the Joint Intl. Conference on Computing and Decision Making in Civil and Building Engineering, Montreal (Canada), 2006, Paper no. IC-10.

[13] J. W. Kim, M. H. Kwon, and Y. H. Lee, "Influence of removed web members in shaping formation for hypar space truss", J. Ocean Eng. Tech., vol. 20, no. 2, pp. 16-21, 2006.

[14] J. W. Kim, Y. H. Lee, and J. H. Doh, "Analysis and test for shaping formation of space truss by means of cable-tensioning", Proceedings of $6^{\text {th }}$ Intl. Conference Steel and Aluminium Struct., London, 2007, pp. 371-378,.

[15] L. C. Schmidt, and S. Selby, "Domical space trusses and braced domes: shaping, ultimate strength and stiffness", Int. J. Space Struct., vol. 14, no. 1, pp. 17-23, 1999.

[16] L. C. Schmidt, and S. Selby, "Shape formation of some dome-like space trusses" Int. J. Space Struct., vol. 16, no. 2, pp. 137-147, 2001.

[17] MIDAS IT, midas FEA - Analysis Reference, 2008

[18] N. M. Punniyakotty, J. Y. Richard Liew, and N. E. Shanmugam, "Nonlinear analysis of self-erection framework by cable-tensioning technique”, J. Struct. Eng. vol. 126, no. 3, pp. 361-370, 2000.

(C) Kim et al.; Licensee Bentham Open.

This is an open access article licensed under the terms of the Creative Commons Attribution Non-Commercial License (http://creativecommons.org/licenses/ by-nc/3.0/) which permits unrestricted, non-commercial use, distribution and reproduction in any medium, provided the work is properly cited. 